\title{
The Role of Small Business in the Region Innovation Ecosystem Formation
}

\author{
Viktoriya E. Barkovskaya ${ }^{1 *[O R C I D ~ 0000-0002-5823-354 X], ~}$ \\ Natalia S. Khoroshavina 1[ORCID 0000-0002-6563-2047], \\ Olga P. Ivanova 2[ORCID 0000-0002-9563-4166] \\ ${ }^{1}$ LEONOV Moscow Region University of Technology, Korolev, Russia \\ ${ }^{2}$ Yaroslav-the-Wise Novgorod State University, Veliky Novgorod, Russia \\ barkovskaya@ut-mo.ru
}

\begin{abstract}
The article is devoted to studying the possibilities and conditions for increasing the role of small business entities operating in the science towns territory in the process of forming and developing the regions innovation ecosystem. A bibliographic review of scientific views on interpreting the "innovation ecosystem" concept is carried out; the author's interpretation of the researched definition is proposed, which most widely reveals its actual essence. The criteria for classifying a territorial entity as a "science town" are outlined; the defining role of science towns in forming the region innovation ecosystem as points of its growth is emphasized. The article presents the positive dynamics of the development of science towns in Russia, as well as small businesses as drivers of their development (on the example of Moscow region). In this regard, the experience of implementing programs of state support for small business in Moscow region has been studied; the scale of financial support has been estimated. The factors hindering the innovative development of small enterprises in science towns have been identified. An innovation ecosystem project is proposed, which is formed, inter alia, by strengthening the interaction between its main actors: the business community, the educational environment, the scientific community, science towns corporations, regional authorities. The main advantages of implementing such a project are noted. The principles of the region innovation ecosystem functioning are determined to achieve the goals of increasing its efficiency and competitiveness. The results of the study are of practical importance in terms of the possibility of their application by regional authorities when implementing programs for the innovative development of science towns and regions in general. In addition, the proposed approach to the formation of an innovation ecosystem can be used by entrepreneurs when developing trajectories for their business development.
\end{abstract}

Keywords: small business, innovations, innovation ecosystems, science town, regional economics

\section{INTRODUCTION}

One of the most important tasks for increasing the efficiency of the national economy development is creating and constructing economic systems drivers of innovative growth in regions. Small enterprises operating in regions with a large concentration of science towns, i. e. territories with high scientific and technical potential.

The theoretical foundations of the innovation ecosystems formation are reflected in the works of modern domestic and foreign researchers
M.A. Izmaylova, M.Y. Veselovsky, O.P. Ivanova, P. Ritala, P. Roundy and others [1-5].

In theoretical studies, the problem of region innovation ecosystems, with the small business significant participation in science towns taken into account, is almost not considered. The abovementioned scientists' research is related to creating classical ecosystems of the educational or industrial sectors. According to the authors, increasing small businesses participation in the science towns territories can become an alternative to the traditional approach to this issue. 
Currently, there are many key problematic issues that hinder the Russian regions innovation ecosystem development, including the R\&D system weakness, insufficient human resources efficiency, lack of state support pragmatism, etc., including the issue of the possibility of increasing the small business involvement in science towns in the region innovation ecosystem formation. The process of creating ecosystems in Russia is characterized by low rates. The small enterprises participation in science towns, due to their inherent properties of flexibility, mobility, innovativeness and scientific and technical orientation, can provide conditions for the sustainability of such systems.

The main elements of the study are presented in the sections of this article. The "Materials and Methods" reflects the purpose, objectives and methods of the research. In the "Results" section, the analysis of the "innovation ecosystem" concept interpretations proposed by the researchers is carried out, its author's definition is proposed; the role of science towns in the region innovation ecosystem formation is outlined; reflects the state of domestic and foreign small business in economic agglomerations; the factors that hinder the innovative development of business entities are indicated; an innovation ecosystem is presented (on the example of Moscow region) with small business participation in science towns; the principles of the innovation ecosystem structures functioning, which ensure its competitiveness, are proposed. The "Discussion" interprets the obtained research results in the context of previously published materials on the research problem. The "Conclusion" indicates the research practical significance and prospects.

\section{MATERIALS AND METHODS}

The purpose of the article is to study the role of small enterprises operating in the science towns territories in the Moscow region innovation ecosystem formation.

To achieve the purpose of the study, the following objectives have been identified:

- to conduct a theoretical review of scientific views in interpreting the "innovation ecosystem" definition and offer its author's interpretation;

- to analyze domestic and foreign experience of small business development in economic agglomerations;

- to determine the factors hindering the innovative development of business entities;

- to develop an approach to the Moscow region innovation ecosystem formation based on the small business involvement in science towns;

- to determine the principles of the innovation ecosystem structures functioning to ensure its competitiveness.

The scientific tools were based on such research methods as analysis, grouping, comparison, abstraction, etc. Methods of economic analysis, factor analysis, graphical data presentation, etc. have been used to analyze the data. The formed methodological apparatus has made it possible to ensure the validity of the study conclusions and practical recommendations.

The consistency of the study is confirmed by similar interim results published by a number of scientists [1-5].

\section{RESULTS}

According to the Russian Venture Company (RVC JSC), the "innovation ecosystem" is considered as a set of interacting elements for the commercialization of the intellectual activity results in order to ensure the intensity and efficiency of the country's economy innovative growth [6]. This approach to definition indicates the interconnectedness of the participating structures in order to provide a favourable environment for the innovative development of Russia.

In the studies of R. Brown, C. Mason, S. Mawson [7], the "innovation ecosystem" is represented as a combination of structures, institutions and organizations aimed at creating intellectual property objects. This definition reveals the creation of a formal or informal association for the intellectual property development and regulation.

J.F. Moore considers this term in the context of the "entrepreneurial ecosystem" in the form of a specific community of various actors implementing innovative projects with interaction and competition [8]. In this case, the "innovation ecosystem" is identified with the "entrepreneurial ecosystem", which seems to be the most relevant in the direction of the problems under consideration.

The researchers mentioned above represent the innovation ecosystem as an association of various economic structures in order to achieve commercial effects. The author's approach proposes the innovation ecosystem concept, which, in our 
opinion, most broadly reveals its essence. The region innovation ecosystem is understood as a set of established local ties of economic entities, institutions, research organizations and authorities aimed at creating new values in order to increase the efficiency of the country's economy and its welfare, meeting the market demands and needs, jointly reacting and adapting to external economic fluctuations.

The most famous innovation ecosystems in Russia are:

- Tomsk region - a territorial ecosystem with a high scientific and educational potential and effective human capital, aimed at supporting student research projects of Tomsk universities;

- Zhigulevskaya dolina in Samara region is a high-tech community created to promote space development, innovative projects in the field of transport, chemistry and energy conservation.

Large foreign innovation ecosystems are:

- Silicon Valley in California (USA) - a zone of innovative technologies with a large concentration of structures and enterprises the activities of which are aimed at creating computer, mobile and software, developing biomedicine, etc.;

- MIT in Boston (USA) - the largest research agglomeration, the main structure of which is the Massachusetts Institute of Technology, which is the center of artificial intelligence and robotics;

- Harvard in Cambridge (USA) - the elite of American universities, which created a scientific and technical association in the areas of engineering and mathematics.

In the Russian Federation, at the legislative level, there are certain conditions under which a territorial entity has the status of a science town, which is a significant element in the innovation ecosystem creation. These conditions include:

- at least $50 \%$ of innovative products in the total production volume;

- at least $20 \%$ of the city-forming complex employees of total employees number;

- at least $20 \%$ of scientific and pedagogical workers of total employees number;

- others.
In other words, the status of a science town is assigned to territorial entities with a more developed scientific and technical complex. For this reason alone, science towns are called upon to be elements of ecosystems and points of territories innovative growth. At the same time, small enterprises, created on the basis of most of the city-forming science towns innovative enterprises, are subordinate to solving the problems of the latter.

Moscow region is the region with the highest concentration of science towns and small enterprises operating on their territories (Figure 1). The most effective of the science towns are Korolev, Dubna, Zhukovsky, Protvino, Pushchino, Reutov.

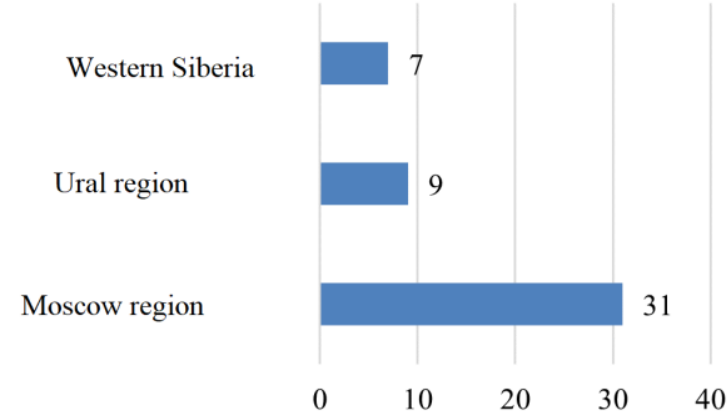

Figure 1. Number of science towns in Russia, units Source: [9]

For years 2018-2020 the number of small businesses in Moscow region is characterized by positive dynamics: the increase was more than 32 thousand units (Figure 2).

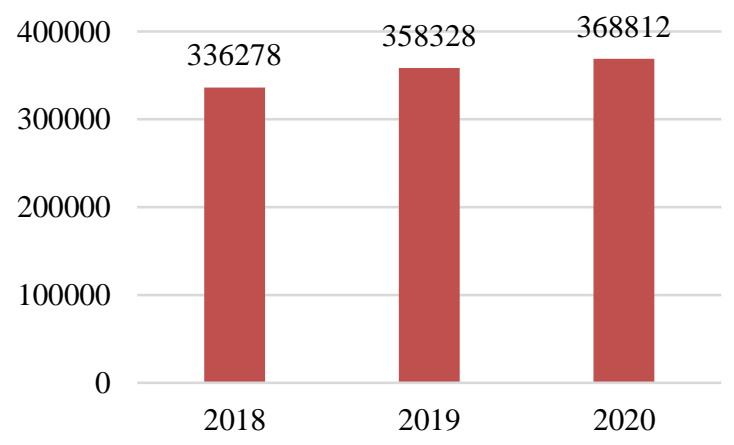

Figure 2. The number of small enterprises in Moscow region, 2018-2020, units

Source: [10]

For comparison: the number of small enterprises in the United States, which is about $19 \mathrm{mln}$ units, the share of those employed in the small business sector $-47.3 \%$ of all employed people in the national economy.

State support for small businesses is of great importance when forming an innovation regional 
and national ecosystem. Russian experience testifies to the existence of such state support programs, namely (using the example of Moscow region):

1) The National Program "Digital Economy of the Russian Federation" (approved by the Order of the Government of the Russian Federation No. 1632-p dated July 28, 2017), which provides for creating a digital economy ecosystem and introducing necessary development institutions and structures, which enhances the importance of digitalization of business, scientific and educational communities, the state and citizens and providing favourable conditions for the innovative activities implementation;

2) "Strategy for the development of small and medium-sized businesses in the Russian Federation for the period up to 2030' (approved by the Order of the Government of the Russian Federation No. 1083-p dated June 2, 2016), aimed at the region innovation systems development;

3) The "Moscow Region Entrepreneurship" Moscow region state program for years 20172024 (approved by the Decree of the Government of Moscow Region No. 788/39 dated October 25, 2016), aimed at the rational distribution of investment, creating new jobs, developing the science-driven enterprises in the region territory.

The main indicator of the level of innovative support for small businesses abroad is the volume of private and public funding for scientific research. For example, in Japan, France and the United States, the private sector invests over $70 \%$ of total funding in science. In addition, about $90 \%$ of applied research is also funded by the private sector. Government institutions participate in small business investment with a smaller contribution: in France this figure is $42 \%$, in the USA and Japan - about $30 \%[11,12]$.

In 2021 Russian budget expenditures on financing fundamental and applied research and innovative developments decreased by $6.3 \%$ compared to 2020 and amounted to 486.1 billion rubles; at the same time, their share in the total state budget expenditures is only $2.7 \%$, which indicates an extremely low level of state financial support, despite the government programs being implemented.

The main factors hindering the innovative development of economic entities in Russia also include: scientific and technical factors (technical and technological backwardness from the world developed countries); financial and economic factors (low level of investment in the development of small enterprises innovative activities); personnel factors (insufficient qualification of small business workers). In addition, high inflation rates, low population incomes, unstable market conditions, etc. should be mentioned, which adversely affects the implementation of all economic entities innovative activities [13, 14].

At present, the small enterprises development is accompanied by the state attempts to propose financial, organizational and economic mechanisms for enhancing their innovative activities. A significant limiting factor here is the communication gap between the authorities and business entities [15-17].

Figure 3 proposes a project of an innovation ecosystem, formed, inter alia, by strengthening the interaction between its main actors.

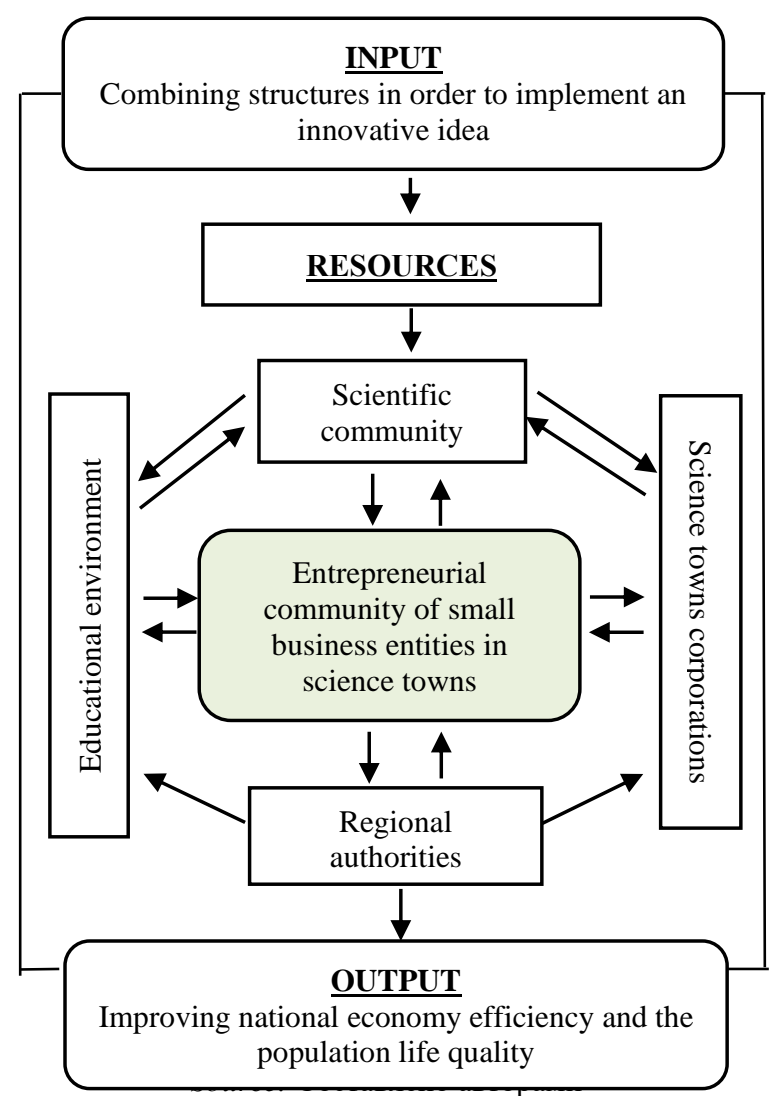

Figure 3. Region innovation ecosystem (project) Source: Compiled by the authors

Contractual cooperation between small businesses and institutions of higher education will provide ecosystem participants with using the 
scientific and educational potential and equipment of those institutions on the basis of which scientific research will be conducted. Therefore, the following opportunities for the innovative activities implementation will be formed (for example, Moscow region):

1) material and technical, consisting in using the potential of venues and equipment for $R \& D$ on the basis of the Engineering Center, Quantorium, IT-laboratories-workshops, which are the parts of the LEONOV Moscow Region University of Technology (Korolev) structure;

2) production and economic opportunities, consisting in the potential use of human resources, partnerships, fixed assets of the region science towns corporations and cityforming enterprises, including S.P. Korolev Rocket and Space Corporation "Energia", "Kompozit" JSC, "Scientific and Production Association of Measuring Equipment" JSC, "Tactical Missiles Corporation" JSC, etc.

The support of the scientific community will help organize joint research and development by all ecosystem participants who offer their own innovative ideas or pursue the goal of attracting new developments. Joint research and development and further commercialization of the resulting product entails the consolidation of rights between the model participants and the formation of an intellectual property management system that allows:

- define exclusive rights to the developed innovative product;

- use intellectual property objects without fear of their "leakage";

- register the right to use an innovative product by third parties for the purpose of generating profit;

- to exclude illegal actions on illegal use of the intellectual activity results.

Integration into a cluster can serve as a way of interaction between small businesses and science towns corporations. It is in corporations that the most significant scientific potential is concentrated, which is urgently needed for the small enterprises development and the innovation ecosystem formation as a whole. These structures, possessing powerful financial, material and technical, scientific and innovative capabilities, create the necessary prerequisites for increasing the ecosystem innovative activity.
In addition, institutions of the higher education system should accept target applicants for training and provide them with professional training for subsequent activities in the structures of small business in science towns. Taking this industry weak financial stability into account, the state should provide substantial financial support for education. In the long term, this direction should focus on obtaining continuous education by entrepreneurs and small business workers to master the necessary innovative competencies and improve their qualifications using the additional professional education programs.

To increase the efficiency of the educational process implementation, the authorities should focus on developing additional measures of state support using direct and indirect methods. In addition, it is necessary to ensure the introduction of innovative digital disciplines into the main professional educational programs. Based on this, the science towns will be provided with professional staff.

In order to achieve efficiency and ensure the competitiveness of the region innovation ecosystem, it is advisable to establish the principles of its functioning (Figure 4).

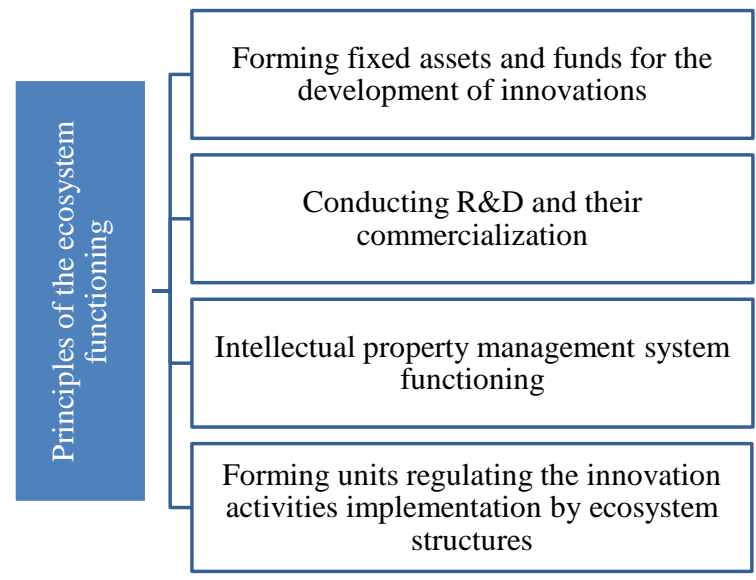

Figure 4. The principles of the region innovation ecosystem functioning

Source: Compiled by the authors

The principles of the region innovation ecosystem functioning reflect its features, on the basis of which institutions, organizations and enterprises, which are elements of the system, are aimed at implementing tasks to increase the efficiency of the country's innovative development.

\section{DISCUSSION}

The author's approach to the region innovation ecosystem formation based on the participation of 
small enterprises located in science towns, activities of which are focused on solving scientific and technical problems, gives development to the existing traditional models of innovation activity ecosystems. The authors have proved that the current economic trends force business entities to find new approaches for the innovative activities development, where small business in science towns can become a key element for improving approaches to the regional systems development.

The foregoing allows us to establish that: 1) additional investments are required for the region ecosystem innovative development, including for $R \& D$; 2) effective region ecosystem management requires providing professional personnel, including through their additional continuous education; 3 ) small enterprises with the properties of flexibility and mobility are effective actors in the region innovation ecosystem formation and development.

The results obtained make it possible to develop the theoretical and methodological foundations of the studied area and can be used in further scientific and applied research.

\section{CONCLUSION}

The proposed approach to the region innovation ecosystem formation is aimed at ensuring the necessary infrastructure conditions for developing and implementing innovations, investments volume, the personnel composition and structure, the commercialization of the innovation products and increasing the innovation processes efficiency.

The application of this approach will enhance the role of small business in the innovation ecosystem formation, which, in general, will contribute to improving the investment and innovation climate in the region and an increase in the population life quality.

The research results acquire practical significance in terms of the possibility of their application by regional authorities when implementing programs for the innovative development of science towns and regions in general. In addition, the proposed approach to the innovation ecosystem formation can be used by entrepreneurs when developing trajectories for their business development.

\section{AUTHORS' CONTRIBUTIONS}

Viktoriya E. Barkovskaya: general project management, analyzing and adding to the article text. Natalia S. Khoroshavina: collecting and processing the materials, preparing the initial text version. Olga P. Ivanova: scientific editing, preparing the final version of the article.

\section{REFERENCES}

[1] M.A. Izmailova, M.Y. Veselovsky, A.A. Stepanov, "Institutional environment development of innovative economy of Russia: problems and solutions", Lecture Notes in Networks and Systems, 2021, vol. 160 LNNS, pp. 164-173. DOI: 10.1007/978-3-030-609290_22

[2] M.Y. Veselovsky, M.A. Izmailova, L.A. Yunusov, I.A. Yunusov, "Quality of digital transformation management on the way of formation of innovative economy of Russia", Quality - Access to Success, 2019, vol. 20(169), pp. 66-71.

[3] O.P. Ivanova, V.A. Trifonov, D.N. Nesteruk, "Crucial factors providing sustainable development of industrial clusters in a priority social and economic development area of single-industry towns", Espacios, 2018, vol. 39(26), p. 26.

[4] P. Ritala, A. Almpanopoulou, "In defense of 'eco' in innovation ecosystem", Technovation, 2017, vol. 60-61, pp. 39-42. DOI: 10.1016/j.technovation.2017. 01.004

[5] P. Roundy, M. Bradshaw, B. Brockman, "The emergence of entrepreneurial ecosystems: A complex adaptive systems approach", Journal of Business Research, 2018, vol. 86, pp. 1-10. DOI: 10. 1016/j.jbusres.2018.01.032

[6] "Five Russian regions presented roadmaps for the implementation of NTI", 2020. (In Russ.). Retrieved from https://www.rvc.ru/pressservice/news/company/160070/?sphrase_id=358 18

[7] R. Brown, C. Mason, S. Mawson, "Increasing 'the vital 6 percent': Designing effective public policy to support high growth firms", NESTA Working Paper, 2014, 14/01.

[8] J.F. Moore, "The Rise of a New Corporate Form", Washington Quarterly, 1998, vol. 21(1), pp. 167-181. DOI: $10.1080 / 01636609809550301$

[9] "73 science cities are located throughout Russia”, 2018. (In Russ.). Retrieved from https://tvil.ru/blog/nahodki-dla-turistov/73- 
naukograda-raspolozilis-po-vsei-territorii-rossii

[10] "Unified register of small and medium-sized businesses”, 2020. (In Russ.). Retrieved from https://rmsp.nalog.ru/

[11] Yu.V. Gnezdova, N.S. Khoroshavina, N.E. Lebedeva, I.V. Balynin, L.D. Sanginova, "The impact of the industry digitization on the economic development of the country", Amazonia Investiga, 2019, vol. 8(21), pp. 633643.

[12]M.A. Izmailova, N.V. Rebrikova, O.V. Kolesnikova, N.S. Khoroshavina, O.A. Shalnova, "Major factors of achievement of quality of corporate management in the Russian medium-sized companies", Quality Access to Success, 2018, vol. 19(166), pp. 7279.

[13]M. Sikyr, N.I. Basmanova, M.S. Abrashkin, "Comparison of study motivation and job expectations of Russian full-time and part-time university students", The International Journal of Educational Management, 2019, vol. 34(3), pp. 549-561. DOI: 10.1108/IJEM-05-2019-0166
[14] O.E. Ivanova, M. Sikyr, M.S. Abrashkin, "Cost management of industrial production based on the system of production rules", Espacios, 2019, vol. 40(30), p. 28.

[15] Y.A. Doroshenko, I.O. Malykhina, I.V. Somina, "Methodology of the formation of a comprehensive support mechanism of innovation and investment development in the region", Lecture Notes in Networks and Systems, 2020, vol. 128 LNNS, pp. 916-923. DOI: 10.1007/978-3-030-46817-0_103

[16] Y.A. Doroshenko, M.S. Starikova, I.V. Somina, I.O. Malykhina, V.N. Riapukhina, "Strategic analysis of competitiveness of high-tech companies as a tool for managing the region's innovative development", Journal of Applied Engineering Science, 2019, vol. 17(4), pp. 579584. DOI: $10.5937 /$ jaes 17-22338

[17] O.P. Ivanova, V.A. Trifonov, D.N. Nesteruk, "Directions and possibilities of predictive analytics in managing the development of single-industry towns", Espacios, 2019, vol. 40(3), p. 04. 